\title{
Alkol-Madde Bağımlılığı Olan Bireylerin Yaşam Kalitesini Etkileyen Faktörler
}

\author{
Elif Aktan MUTLU ${ }^{1}$
}

\begin{abstract}
Özet: Dünya sağlık örgütü, sağlığı bedensel, ruhsal ve sosyal iyilik hali olarak tanımlar. Klasik olan yaklaşımda mevcut organın hastalığının iyileştirilmesi ile "iyileşme " tanımlanırken, son 40 yıldır sağlık hizmetinin çıktılarının başka şekillerde de ele alınması gerektiği konusunda görüş birliği oluşmuştur. Yaşam kalitesi kavramı sağlığın tanımından yola çıkılarak şekillenen bir kavramdır. Bu çalışmaya Bursa Devlet Hastanesi Amatem Kliniğine ayaktan başvuran 80 hasta alınmıştır. Hastalara klinisyenin hazırladığı sosyodemografik veri formu ve Dünya sağlık örgütünün hazırladığı yaşam kalitesi anketi (WHOQL) uygulanmıştır. Çalışmamızın sonucuna göre alkol ve/veya madde bağımlılığı olan bireylerde yaşam kalitesinin arttıran tek değişkenin remisyon süresinin uzaması olduğu görülmüştür. Hastaların yaşam kaliteleri eğitim, medeni durum, adli ceza durumu, çalışma durumu, teşhis (alkol veya madde bağımlısı olmak), yalnız yaşayıp yaşamama durumuna göre değişmemektedir.Remisyon süresinin uzaması, bağımlı hastalarda yaşam kalitesini artıran en önemli faktördür.Diğer sosyodemografik özelliklerin yaşam kalitesinin artmasına katkıda bulunmaması bağımlılığın diğer hastalıklardan farklı olarak daha toplumsal, ailesel, hukuksal, bedensel, iş hayatını etkileyen, kişinin akademik/iş verimini azaltan bir hastalık olmasından kaynaklanabilir.
\end{abstract}

Anahtar kelimeler: Alkol, madde, bağımlılık, yaşam kalitesi

\section{Factors Affecting The Quality of Life of Individuals With Alcohol-Substance Addiction}

\begin{abstract}
World health organization defines health as physical, mental and social well-being. While the classical approach defines 'healing' as the healing of the disease in existing organ, for the last 40 years, there has been a consensus that the outcomes of health care should be handled in other ways. The concept of the quality of life is a concept shaped by the definition of health.Eighty patients who applied to Amatem Clinic of Bursa State Hospital were included in this study. The sociodemographic data form prepared by the clinician and the quality of life questionnaire prepared by the World Health Organization (WHOQL) were administered to the patients.According to the results of our study, the only variable that increases the quality of life in alcohol and / or substance addicts is prolonged remission period. The quality of life of the patients does not vary according to education, marital status, criminal justice status, working status, diagnosis (being addicted to alcohol or substance), living alone or not.Prolonged remission time is the most important factor that improves the quality of life in addicted patients. The fact that other sociodemographic characteristics do not contribute to the increase in the quality of life may be due to the fact that -unlike the other disease- addiction is a disease that affects social, familial, legal, physical, business life and decreases the academic / work productivity of the patient.
\end{abstract}

Key words: Alcohol, substance, addiction, quality of life

${ }^{1}$ Dr, Bursa Şehir Hastanesi Psikiyatri, Nilüfer/ Bursa

Address of correspondence/ Yazışma adresi:Dr. Elif Aktan, Bursa Şehir Hastanesi Psikiyatri, Nilüfer/ Bursa, E-mail: aktanazer@hotmail.com

Date of Received/Geliş Tarihi: 10.10.2019, Date of Revision/Düzeltme Tarihi: 02.11.2019, Date of Acceptance/Kabul Tarihi: 07.11.2019

Citing/ Referans Gösterimi: Mutlu, E.A. (2019). Alkol-Madde Bağımlılı̆̆ı Olan Bireylerin Yaşam Kalitesini Etkileyen Faktörler. Kıbrıs Türk Psikiyatri ve Psikoloji Dergisi, 1(Özel Sayı.1): 50-52 doi:10.35365/ctjpp.19.special1.14 


\section{Giriş}

Dünya sağl1k örgütü, sağlığı bedensel, ruhsal ve sosyal iyilik hali olarak tanımlar. Klasik olan yaklaşımda mevcut organın hastalığının iyileştirilmesi ile "iyileşme " tanımlanırken, son 40 yıldır sağlık hizmetinin çıktılarının başka şekillerde de ele alınması gerektiği konusunda görüş birliği oluşmuştur. Esasen ihtiyaçlardan ortaya çıktığı söylenebilir. Ortaya çıkarıcı sebepler ise sağlık teknolojisindeki gelişmeler, ilaç çalışmalarındaki gelişmeler, beklenen yaşam süresinin artması gibi nedenler olabilir. Yaşam kalitesi kavramı sağllğın tanımından yola çıkılarak şekillenen bir kavramdır. Özellikle kronik hastalarda giderek artan bir öneme sahiptir.

Alkol-madde bağımlılıkları da kronik, ruhsal hastalıklar sınıfındadır. Ruhsal hastalıklar kişinin hayatını ruhsal, fiziksel, sosyal, mesleki, ekonomik ve birçok alanda etkilemektedir (Karimi \& Brazier, 2016, Akvardar,2006).

Ülkemizde alkol madde bağımlılığı alanında yaşam kalitesi ile ilgili çok fazla literatür bulunmamaktadır. $\mathrm{Bu}$ çalışmada alkol ve/veya madde bağımlılığ 1 olan bireylerin yaşam kalitelerinin bazı sosyodemografik ve tıbbi parametrelerle kıyaslanması amaçlanmıştır.

\section{Metod}

Bu çalışmaya Bursa Devlet Hastanesi Amatem Kliniğine ayaktan başvuran 80 hasta alınmıştır. Hastalara klinisyenin hazırladığ 1 sosyodemografik veri formu ve Dünya sağlık örgütünün hazırladığı yaşam kalitesi anketi (WHOQL) uygulanmıştır. Hastaların teşhisleri ICD 10 kriterlerine göre konulmuş olup, muayene ile ilgili sosyodemografik bilgilerine hastane kayıtlarından ulaşılmıştır. Hastaların hepsinden yazılı onam alınmıştır. Psikotik bozukluk benzeri akıl sağlığını etkileyecek düzeyde ek hastalığı olan hastalar çalışmaya alınmamıştır.

WHOQL:Dünya sağlık örgütünün hazırladığı yaşam kalitesi ölçeğidir. 27 sorudan oluşmuştur. Son soru kültüre özgü sorudur. 4 alt ölçeği vardır. Bunlar bedensel, ruhsal, çevresel, sosyal alt ölçeklerdir. İlk iki soruda kişinin kendi algıladığı sağlık ve yaşam kalitesi sorulmuştur. Puan düzeyi arttıkça yaşam kalitesinin arttığı düşünülür. Türkçe geçerlilik, güvenilirlik çalışması yapılmıştır(Eser et al., 1999).

\section{İstatistiksel İncelemeler}

Çalışmada elde edilen bulgular değerlendirilirken, istatistiksel analizler için NCSS (Number Cruncher Statistical System) 2007 Statistical Software (NCSS LLC, Kaysville, Utah, USA) programı kullanıldı (Hintze, 2007). Çalışma verileri değerlendirilirken tanımlayıcı istatistiksel metodların (Ortalama, Standart sapma, medyan, sıklık ve oran) yanı sira niceliksel verilerin karşılaştırılmasında normal dağılım gösteren parametrelerin gruplar arası karşılaştırmalarında Oneway Anova test ve farklılığa neden çıkan grubun tespitinde Bonferroni test; iki gruba göre değerlendirmelerde Student $\mathrm{t}$ test kullanıldı. Değişkenler arası ilişkilerin değerlendirmelerinde Pearosn ve Spearman korelasyon analizi kullanıldı. Niteliksel verilerin karşılaştırılmasında ise Fisher Freeman Halton test kullanıldı. Sonuçlar \% 95'lik güven aralığında, anlamlılık $\mathrm{p}<0.05$ düzeyinde değerlendirildi.

\section{Bulgular}

Başvuran hastaların \%93,8'i $(n=75)$ erkek, $\% 6,3$ 'ü $(n=5)$ kadındır. Hastaların \%15'i $(\mathrm{n}=12)$ son bir yılda madde veya alkol kullanmamıştır. Tablo 1'de hastaların bazı sosyodemografik özellikleri özetlenmiştir.

Hastaların yaş ortalaması 35,9 yıl, son bir yıldaki ortalama takip muayene sayıs 4,8 adet, son bir yıldaki remisyon süresi ortalama 4,1 ay, toplam hastalık süresi ise ortalama 13,8 y1l, tedaviye ilk başvurma yaşı 33,7 yıl, tedavide kalma süresi 22,6 aydır.

Kişinin algıladığ yaşam ve sağlık kalitesi son bir yıldaki takip sayısı, remisyon süresi arttıkça artmaktadır. Ayrıca tedavide kalma süresi arttıkça kişinin algıladığı yaşam kalitesinin arttığ görülmektedir $(\mathrm{p}<0.05)$.Cinsiyet, medeni durum, eğitim durumu, çalışma durumu, teşhis, kiminle yaşadığı, ek fiziksel hastalık durumu ve adli ceza durumuna göre kişinin algıladığ kalitesinin değişmediği görülmüştür $(\mathrm{p}>0.05)$. Aynı şekilde cinsiyet, medeni durum, eğitim durumu, teşhis, kiminle yaşadığı, ek fiziksel hastalık durumu ve adli ceza durumuna göre kişinin algıladığı sosyal baskının değişmediği $(p>0,05)$, sadece çalışma durumuna göre işsiz bireylerin daha fazla sosyal baskı hissettikleri $(p<0,05)$ görülmüştür. Remisyon süresi ile yaşam kalitesi ölçeği tüm alt boyutları olan bedensel, sosyal, ruhsal, çevresel ve toplam puanları arasında istatistiksel olarak anlamlı ilişki saptanmışırı (sırasıyla r:0,366; r:0,317; r:0,279; r:0,392; r:0,405). Remisyon süresi arttıkça yaşam kalitesi de artmaktadır. Ancak medeni durum, çalışma durumu, eğitim düzeyi, teşhis tipi, yalnız yaşayıp yaşamadığı, ek hastalık durumu, adli ceza görüp görmediğine göre yaşam kalitesinin alt ölçekleri ve toplam yaşam kalitesi puanları değişiklik göstermemişlerdir (Tablo 2).

\section{Tartıșma}

Yaşam kalitesi sağlık düzeyini ölçmenin günümüzdeki en önemli göstergelerindendir. Remisyon süresinin uzaması, hastayı mümkün olabildiğince tedavide tutmak, sık takip muayeneleri uygulamak bağımlı hastalarda yaşam kalitesini artıran faktörlerdir. Eğitim, gelir düzeyi, iş durumu gibi sosyodemografik özelliklerin yaşam kalitesinin artmasına katkıda bulunmaması bağımlılı̆̆ın diğer hastalıklardan farklı olarak daha toplumsal, ailesel, hukuksalyaptırımları olan, bedensel, iş hayatını etkileyen, kişinin akademik/iş verimini azaltan bir hastalık olmasından kaynaklanabilir (Giri et al., 2016, Muller et al., 2016). Bir diğer etken de bu kişilerin yaşadığ toplumsal veya tıbbi stigmatizasyon olabilir(Mutlu et al., 2014, Arıkan et al., 2004).Hastaları tedavide tutmak, gerekli ilaç tedavilerine ulaşmalarını kolaylaştırmak ve bu tedavileri almalarını sağlamak, takip muayenelerini aksatmamaları için gerekli girişimlerde bulunmak (sosyal çalıșmacı desteği, telefonla ulaşmak, ev ziyaretleri, randevu almayı kolaylaştırıcı bilgi işlem programları, hastaların 24 saat esasına göre takip programlarına alınması gibi) bağımlılıkla mücadelede hedeflerimiz olmalidir. 


\section{Kaynaklar}

Akvardar, Y., Akdede, B. B., Özerdem, A., Eser, E., Topkaya, S., Alptekın, . Psychiatry And Clinical Neurosciences, 2006. Assessment Of Quality Of Life With The Whoqol- Bref In A Group Of Turkish Psychiatric Patients Compared With Diabetic And Healthy Subjects. 60, 693-699.

Arıkan, Z., Yasın Genç, D., Çetın Etık, D., Aslan, S. \& Parlak, İ. Journal Of Dependence, 2004. Stigmatization Of The Patients And Their Relatives İn Alcohol And Other Substance Dependencies. 5, 52-56.

Eser, E., Fidaner, H., Fidaner, C., Eser, S. Y., Elb1, H. \& Göker, E. Psikiyatri Psikoloji Psikofarmakoloji (3p) Dergisi, 1999. Whoqol-100 Ve Whoqol-Bref'in Psikometrik Özellikleri. 7, 23 40 .
Gırı, O., Srıvastava, M., Shankar, R. Journal Of Psychosocial Rehabilitation And Mental Health, 2016. A Comparative Study Of Quality Of Life, Social Support And Dysfunction İn Alcohol Dependent Men Attending A De-Addiction Clinic İn India. 3, 61-68.

Hıntze, J. 2007. Ncss 2007. Ncss, Llc. Kaysville, Utah, Usa.

Karımı, M. \& Brazıer, J. Pharmacoeconomics, 2016. Health, Health-Related Quality Of Life, And Quality Of Life: What İs The Difference? 34, 645-649.

Muller, A. E., Skurtveit, S., Clausen, T. Health And Quality Of Life Outcomes, 2016. Many Correlates Of Poor Quality Of Life Among Substance Users Entering Treatment Are Not AddictionSpecific. 14, 39 .

Mutlu, E., Bılıcı, R. \& Çetın, M.K. Bă̆ımlılık Dergisi, 2014. Sağlık Çalışanlarının Bağımlılık Hakkında Tutumları. 15, 118123. 